\title{
Beta Estimates of shares on the JSE Top 40 in the context of Reference-Day Risk
}

\author{
Christopher Baker · Kanshukan \\ Rajaratnam · Emlyn James Flint
}

\begin{abstract}
A topic of interest in the finance world is measuring systematic risk. Accurately measuring the systematic risk component - or Beta - of an asset or portfolio is important in many financial applications. In this work, we consider the efficiency of a range of Beta estimation methods commonly used in practice from a reference-day risk perspective. We show that, when using the industry standard data sample of five years of monthly returns, the choice of referenceday used to calculate underlying returns has a significant impact on all of the Beta estimation methods considered. Driven by this finding, we propose and C. Baker Section of Actuarial Science, University of Cape Town, South Africa Tel.: +27-21-6502480

Fax: +27-21-6504487

E-mail: bkrchr004@myuct.ac.za

K. Rajaratnam [corresponding author]

Department of Finance \& Tax, and the African Collaboration for Quantitative Finance \& Risk Research, University of Cape Town, South Africa

Tel.: +27-21-6502480

Fax: +27-21-6504487

E-mail: kanshukan.rajaratnam@uct.ac.za

E.J. Flint

Peregrine Securities, Cape Town, South Africa \& Department of Mathematical Sciences and Applied Mathematics, University of Pretoria, South Africa E-mail: emlynf@peregrine.co.za
\end{abstract}


test an alternative non-parametric bootstrap approach for calculating Beta estimates which is unaffected by reference-day risk. Our primary goal is to determine a point-estimate of Beta, independent of reference-day. Keywords: reference-day risk, bootstrap, systematic risk, Beta.

\section{Introduction}

Significant research has been conducted into the evaluation of the risk of shares. The total risk of a share is made up of systematic risk (market-related) and specific risk (specific to the company and not correlated with the market). The market model is widely used to model the returns (proportional monthly increase in price) of a share. The market model states that the returns earned on a share are a linear function of the returns of the market index plus an error term:

$$
R_{t}=\alpha+\beta M_{t}+e_{t},
$$

where $R_{t}$ is the return on the share at time $t, M_{t}$ is the return on the market index at time $t$, and $e_{t}$ is a zero-mean error term, which is uncorrelated to $M_{t}$ or $R_{t}$. The systematic risk of a share is represented by $\beta$, the specific risk is represented by the intercept $\alpha$ and resulting error is represented by $e_{t}$.

The values $\beta$ and $\alpha$ are not directly observable and therefore need to be estimated. Estimates for the values of the intercept and slope in the market model are calculated using Observed Least Squares ( $\hat{\alpha}$ and $\hat{\beta}$ respectively) such that:

$$
\hat{\beta}=\frac{\operatorname{cov}(R ; M)}{\operatorname{var}(M)}, \quad \hat{\alpha}=\bar{R}-\hat{\beta} \bar{M},
$$

where $\bar{M}$ is the average market return, $\bar{R}$ is the average share return, $\operatorname{cov}(R ; M)$ is the covariance between the market returns and the share returns, and $\operatorname{var}(M)$ is the variance of the market returns.

By convention, the systematic risk is estimated from 60 monthly log returns, where monthly returns are the percentage change in share price from the last day of a month to the last day of the following month. However, one 
could also estimate the systematic risk using monthly returns from the $15^{\text {th }}$ day of a month to the $15^{\text {th }}$ day of the following month. Using different days in this manner creates the opportunity to calculate more than 20 different Beta estimates for the same share over a 5 year period, thus creating reference-day risk, the risk of mis-estimation because of the reference-day used to calculate returns, in the estimation of the systematic risk.

Reference-day risk has been assumed to be negligible by academics because pairs of corresponding monthly returns, with different reference-days, contain at least one common daily return and it is therefore assumed that reference-day risk is insignificant in comparison to estimation risk (Acker and Duck, 2007). The literature investigating reference-day risk when estimating systematic risk has verified its existence, even after adjusting Beta estimates to correct for thin-trading and the non-stationarity/mean-reversion characteristics of systematic risk. However, this has only been confirmed for shares listed in the $\mathrm{S} \& \mathrm{P} 500$. This raises the questions whether we may create a reference-day independent estimate of Beta.

In this paper, our focus is in determining a point-estimate of Beta independent of reference day on the Johannesburg Top 40 (JSE Top 40). First we show reference day risk exists on the JSE Top 40. Then we make adjustment traditionally used to reduce the effect of extreme reference-day variability. Then we use a non-parametric bootstrap approach to determine Beta estimates which are independent of reference-day risk.

This paper is organised as follows. Section 2 reviews the literature on the subject. Section 3 details the data and a basic assumption in this study. Section 4 addresses three topics. The first topic is the existence of reference-day risk in estimating systematic risk for shares making up the JSE Top 40 index. The second topic is the persistence of reference-day risk after the Blume (1971), Dimson (1979) and Vasicek (1973) adjustments are made to the estimates of systematic risk. The third topic, and final part of Section 4, is the proposal of a reference-day independent measure of systematic risk that involves creating a bootstrapped Beta distribution from which we obtain a point-estimate of 
systematic risk. This estimate is evaluated and then applied to the shares making up the JSE Top 40 index. Finally in Section 5, we summarize and conclude our findings.

\section{Literature Review}

The Beta estimate plays an integral role in the Capital Asset Pricing Model (CAPM), which was created by Sharpe (1963) and is used in capital budgeting, investment performance evaluation, risk management and business valuation (Gonzalez et al, 2014). A mis-estimation of systematic risk due to choice of reference-day could have serious repercussions to individual investors and companies alike.

Acker and Duck (2007) prove the existence of reference-day risk associated with monthly returns implicit in shares listed on the S\&P500 index and go on to explore the level of reference-day risk implicit in estimates of systematic risk after having adjusted the estimates by the Blume (1971) regression method, the Vasicek (1973) Bayesian method and the Dimson (1979) adjustment for thin trading.

Results from the investigation by Acker and Duck (2007) indicate that monthly returns are highly sensitive to reference-day risk, revealing that the mean monthly return of a share over 5 years ranged between -0.239 and +0.934 depending on the reference-day. Furthermore, the investigation finds that the Beta of one share was calculated at -2 using one reference-day and +2 using another. This means that the share's returns could be interpreted as negatively correlated with the market or positively correlated with the market, depending on which reference-day is used. Acker and Duck (2007) conclude that the Blume (1971) and Vasicek (1973) adjustment methods reduce the cases of extreme reference-day variability, but the Dimson (1979) method has no effect on the reference-day variation.

The data-dependency of the results of Acker and Duck (2007) is investigated by Dimitrov and Govindaraj (2007) by replicating the investigation of 
Acker and Duck (2007) using data from the Centre for Research in Security Prices instead of Datastream. The results of Dimitrov and Govindaraj (2007) reveal similar sensitivity to reference-day choice in monthly returns, confirming the existence of reference-day risk in companies listed on the S\&P500.

Gonzalez et al (2014) investigate the sensitivity to reference-day choice in different methods for estimating Beta of shares listed on the S\&P500. The methodology of Gonzalez et al (2014) differs from the works of Acker and Duck (2007) and Dimitrov and Govindaraj (2007) by extending the analysis to the sensitivity of Betas that have been adjusted using the t-distribution method (shown by Cademartori et al (2003) to incorporate the effect of outliers in estimating systematic risk). The results propose that the t-distribution method for calculating Betas most significantly reduces the reference-day variation in comparison to methods by Blume (1971) and the OLS estimate.

Bradfield (2003) provides a comprehensive guide to estimating systematic risk in a South African context and emphasises the need for adjustments to Betas in order to correct for bias arising from thin trading.

Thin trading occurs when a share is not frequently traded and results in the month end price being set by a trade made earlier in the month, and not on the last day of the month. This results to a downward bias in the OLS estimate of systematic risk because the covariance term of the OLS Beta is reduced (Dimson, 1979). There are two approaches for adjusting Beta estimates for thin trading: the trade-to-trade estimator (discussed by Marsh (1979), Dimson (1979) and Bowie and Bradfield (1993)) and the Cohen estimators (including methods by Scholes and Williams (1977), Dimson (1979), Cohen et al (1983)).

Additionally, Bradfield (2003) discusses the regression bias property of Beta estimates, first documented by Blume (1971). The regression bias states that a Beta that is significantly higher than average (of all listed shares) is overestimated, and conversely, an estimate that is significantly lower than average is underestimated. The average Beta estimate of the market should be 1 because market-related systematic risk of the market index is one: market returns move 
in line with market returns exactly (trivially). Bradfield (2003) suggests that this bias is corrected by the Bayesian adjustment suggested by Vasicek (1973).

Bradfield (2003) claims that the most important adjustments to Beta estimates in South Africa are adjustments for thin trading and Bayesian adjustments, thereby making the investigation of the effect of these adjustments on reference-day risk in South Africa all the more relevant. In South Africa, published Betas, such as those published by BNP Paribas Cadiz Securities (2014), are adjusted for thin trading and make use of Bayesian adjustments for regression bias.

The downward bias mentioned by Bradfield (2003) occurs because infrequent trading (of a particular share) results in an underestimate of the covariance between the market index and the share. Since the OLS Beta estimate of a share is $\hat{\beta}=\frac{\operatorname{cov}(R ; M)}{\operatorname{var}(M)}$, the systematic risk is underestimated for thinly traded shares because the numerator is reduced. On the contrary, because the mean Beta for all shares on an index is 1, the Beta for frequently traded shares is thus upwardly biased.

Three alternative methods for estimating systematic risk in light of thin trading are mentioned and evaluated by Dimson (1979). The first method, involving use of lagged market returns in the market model, is shown to be justified only if the market does not experience high levels of infrequent trading. The second method evaluated is the trade-to-trade method that makes use of returns estimated between trades. These returns are regressed on movements in the market index between trades. The trade-to-trade method requires transaction times and corresponding prices for all trades of a share on the index, making it difficult to use in pracatice. The third method mentioned is the one proposed by Scholes and Williams (1977) where systematic risk is estimated using synchronous and non-synchronous market returns as the explanatory variable for the trade-to-trade returns. The Scholes and Williams (1977) method also requires full transaction history and does not make use of share prices for a period not preceded or succeeded by a trade. 
Dimson (1979) proposes the Aggregated Coefficients (AC) method to estimate the systematic risk of a share. The AC method requires neither full transaction history nor continuous trading to occur. The AC method assumes that returns are generated by the market model using measured returns $\hat{R}_{t}$ and $\hat{M}_{t}$ and the OLS estimates of regression coefficients, $\hat{\beta}$ and $\hat{\alpha}$,

$$
\hat{R}_{t}=\hat{\alpha}+\hat{\beta} \hat{M}_{t}+e_{t} .
$$

The AC method states that the true systematic risk $(\beta)$ can be estimated from price data that is subject to infrequent trading when one regresses the observed share return $R_{t}$ against lagged, matched and leading market returns $M_{t+k}$ (a full derivation can be found in Dimson (1979))

$$
\hat{R}_{t}=\hat{\alpha}+\sum_{k=-n}^{n} \beta_{k} M_{t+k}+e_{t}
$$

where $\beta_{k}$ is the regression coefficient for the dependent variables, $M_{t+k}$. Consequently, the Beta estimate $\hat{\beta}$ is calculated as the aggregated coefficients in the regression (Dimson, 1979):

$$
\hat{\beta}=\sum_{k=-n}^{n} \beta_{k} .
$$

Dimson (1979) compares the Beta estimate derived using the AC method against the Scholes and Williams (1977) method, trade-to-trade method and standard OLS Beta estimation by using simulated data with a true Beta of one. The comparison highlights four points: firstly, there is significant bias in Beta estimation using OLS when infrequent trading occurs; secondly, the tradeto-trade method is the most efficient in estimating Beta under thin trading; thirdly, the Scholes and Williams (1977) method is an inefficient estimator although it does not suffer bias due to infrequent trading; and finally, the AC method only suffers non-trading bias in the least frequently traded decile but is shown to be a more efficient estimator than that of Scholes and Williams (1977). The superior efficiency and non-requirement of transaction history 
confirms the choice of using the Dimson (1979) method over the Scholes and Williams (1977) method to adjust for thin trading in this paper, recalling the necessity of adjusting for thin trading on the JSE (Bradfield, 2003).

The second adjustment to Beta estimates investigated under reference-day risk in Acker and Duck (2007) is the method proposed by Blume (1971) when investigating the stationarity of Beta estimates. Blume (1971) creates portfolios of shares according to the magnitude of estimated systematic risk and estimates the systematic risk for the portfolios for consecutive, non-overlapping periods. The results show a tendency for the portfolios with the highest Beta estimates $(\geq 1)$ to decline monotonically towards 1 . The portfolios with the lowest Beta estimates tend towards 1 over time. ${ }^{1}$

Blume (1971) regresses period 2 Betas $\left(\hat{\beta}_{2}\right)$ for individual securities on those obtained from period $1\left(\hat{\beta}_{1}\right)$ according to the following regression (where $a$ and $b$ are regression coefficients and $e_{t}$ is a zero mean error term):

$$
\hat{\beta}_{2}=a+b \hat{\beta}_{1}+e_{t}
$$

The mean squared errors of the actual correlation of share returns to market returns against the estimated value of the risk (the Beta estimate) for both the adjusted and unadjusted Beta estimates are calculated. The mean squared error of the adjusted estimates is consistently smaller than that of the unadjusted Beta estimates, concluding that the Beta estimates adjusted according to previous estimates result in higher accuracy even though the rate of regression is not necessarily constant (Blume, 1971).

The final adjustment investigated in Acker and Duck (2007) is that put forward by Vasicek (1973), who presents a method for generating Bayesian estimates for Beta used in the market model. The prior distribution used is normal with mean $b^{\prime}$ and variance $s_{b}^{\prime 2}$. The parameters $b^{\prime}$ and $s_{b}^{\prime 2}$ are the sample mean and variance (respectively) of the OLS Beta estimates calculated for shares in the index.

1 All Betas were positive in Blume (1971). 
Vasicek (1973) indicates that the properties of the OLS Beta estimate do not represent satisfactory conditions for Beta estimation, even after acknowledging that the OLS Beta estimate is the unbiased estimator that obtains the lowest quadratic error.

The particular property that Vasicek (1973) challenges is:

$$
\mathrm{E}[\hat{\beta} \mid \beta]=\beta .
$$

The above property describes the mean of the estimator, assuming that the true value of Beta is known. However, one would not need an estimator if the $\beta$ is known. The reverse of the above condition is true: one wants to make an inference on $\beta$ given an estimate $\hat{\beta}$. Vasicek (1973) voices the need for an estimate such that the true value of $\beta$ has an equal probability of lying above and below the Beta estimate $\hat{\beta}$.

Using the normal prior distribution with mean $b^{\prime}$ and variance $s_{b}^{\prime 2}$, Vasicek (1973) shows that the posterior distribution of Beta is normally distributed with mean $b^{\prime \prime}$ and variance $s_{b}^{\prime \prime 2}$, where $\hat{\beta}$ is the OLS estimate of the systematic risk and:

$$
\begin{aligned}
b^{\prime \prime} & =\frac{\left(b^{\prime} / s_{b}^{\prime 2}+\hat{\beta} / s_{b}^{2}\right)}{\left(1 / s_{b}^{\prime 2}+1 / s_{b}^{2}\right)}, & s_{b}^{2} & =\frac{s^{2}}{\sum\left(M_{t}-\bar{M}\right)^{2}}, \\
s_{b}^{\prime \prime 2} & =\frac{1}{\left(1 / s_{b}^{\prime 2}+1 / s_{b}^{2}\right)}, & s^{2} & =\frac{\sum\left(R_{t}-\hat{\alpha}-\hat{\beta} M_{t}\right)^{2}}{(T-2)},
\end{aligned}
$$

where $t$ is the time step, with $t=1,2, \ldots, T$.

The mean of the posterior distribution $b^{\prime \prime}$ is used as the Bayesian estimate for systematic risk. Bayesian estimators are preferred to OLS estimates for two reasons: firstly, Bayesian estimates minimise the loss of accuracy due to mis-estimation whereas OLS estimates minimise the loss of accuracy due to sampling error; and secondly, Bayesian estimators incorporate previous information and sampling knowledge into the estimate of systematic risk (Vasicek, 1973).

The literature investigating reference-day risk for Beta on the S\&P500 has verified its existence even after the relevant adjustments. Our focus is on the 
JSE Top 40. This raises the questions: "Is there Beta-related reference-day risk implicit in the JSE Top 40?"; "What is the effect of adjusting Betas on reference-day risk in the JSE Top 40?"; and "Can we create a reference-day independent estimate of systematic risk?". In the remainder of the paper, we estimate Betas independent of reference-day.

\section{Data and Basic Assumptions}

This paper uses the daily closing level of the All Share Index (ALSI) and closing prices of shares making up the JSE Top 40 index over the period January 2000 to July 2015. The data is extracted from DataStream, where the share prices with code "P" and ALSI level with code "PI" are taken. The companies making up the JSE Top 40 index over the period are listed in Appendix A. Section 4 is based on the market model, $R_{t}=\alpha+\beta M_{t}+e_{t}$, which states that a share's returns can be modelled using market returns, where $\beta$ is the systematic risk of the company. The systematic risk can be estimated by $\hat{\beta}$, where $\hat{\beta}=\frac{\operatorname{cov}(R ; M)}{\operatorname{var}(M)}$. We refer to the estimate of systematic risk as Beta.

In Section 4.3.1 we assume that when one calculates Beta, we are sampling a random variable from a distribution that approximates the true systematic risk of a company. Following Dimson (1979), we assume that share prices are log normally distributed when simulating monthly returns.

\section{Method, Results and Analysis}

In this section we establish the existence of reference-day risk and demonstrate its persistence after adjusting Betas using common adjustments.

4.1 Investigating the Existence of Reference-Day Risk

The monthly share prices (and index level) data is organised according to trading days, the first trading day of a month does not necessarily fall on the 
first calendar day of the month. Log returns for the shares and the index are calculated for the period January 2010 to December 2014 for each of the 20 trading days (used because every month has at least 20 trading days).

Betas are calculated for each share across all trading days. We test the different Betas for a particular share for statistically significant difference by creating a model that includes the returns on the share and market for all trading days. The model is restricted to test the hypothesis, $H_{1}$, that all of the Betas for a company are equal. Following that, the model is restricted to test the hypothesis, $H_{2}$, that the largest and smallest Betas for the same company, but calculated using different trading days, are equal:

$\underline{\text { Test } 1}$

$H_{0}: \beta_{i}=\beta_{j} \forall i, j$

$H_{A}: \beta_{i} \neq \beta_{j}$ for some $i, j$

Test 2

$H_{0}: \max \beta=\min [\beta]$

$H_{A}: \max \beta \neq \min [\beta]$

The Betas that are compared in the above hypothesis test are outputs of different regressions, with each regression using different set of data. In order to test the hypothesis that the Betas are equal, we approximated an $F$-statistic using the Pillai-Bartlett trace (see Fox et al (2013) for more). ${ }^{2}$

Upon first inspection of the unadjusted Betas, it is clear that there is an effect on Beta when the reference-day is varied. Using the ranges of Beta, the effect of change in reference-day is most pronounced in AngloGold Ashanti, Anglo American Platinum and Brait SE (see Table 1). Similarly, there are also companies for which Beta appears to be relatively constant. Using the ranges of Beta, there appears to be little effect in Mondi PLC, Remgro and Standard Bank across trading days. Beta remains at a relatively constant level for these three companies across trading days. A summarized table for all companies on the JSE Top 40 can be found in Appendix B.

\footnotetext{
${ }^{2}$ We use the linearhypothesis function on $\mathbf{R}$ to determine the probability of nullhypothesis in Test 1 and Test 2 .
} 


\begin{tabular}{|c|ccc|ccc|}
\hline \multirow{2}{*}{} & \multicolumn{3}{|c|}{ Smallest Ranges } & \multicolumn{3}{c|}{ Largest Ranges } \\
& MNL & REM & STA & AAP & BRA & AAG \\
\hline Max & 1.225 & 0.967 & 0.872 & 1.590 & 0.950 & 1.656 \\
Min & 1.016 & 0.721 & 0.621 & 0.897 & 0.089 & 0.499 \\
Range & 0.210 & 0.245 & 0.251 & 0.693 & 0.861 & 1.157 \\
Mean & 1.121 & 0.872 & 0.767 & 1.273 & 0.579 & 0.794 \\
Variance & 0.004 & 0.004 & 0.005 & 0.036 & 0.072 & 0.079 \\
Median & 1.104 & 0.876 & 0.786 & 1.266 & 0.647 & 0.723 \\
\hline $\operatorname{Pr}\left(H_{1}\right.$ True $)$ & 1.000 & 1.000 & 1.000 & 0.987 & 0.992 & 0.968 \\
$\operatorname{Pr}\left(H_{2}\right.$ True $)$ & 0.313 & 0.495 & 0.379 & 0.081 & 0.041 & 0.045 \\
\hline
\end{tabular}

Table 1: Smallest and Largest ranges in unadjusted Beta

The differences in Beta could have adverse repercussions for share portfolio construction. For example, consider a risk-averse investor who wishes to build a share portfolio that is weakly correlated with the market (positive Beta less than one). If the investor happens to calculate Beta for AngloGold Ashanti and Brait on a day that yields the lowest Betas, the investor could achieve an overall Beta for his portfolio ranging between 0.089 - if the portfolio is made entirely of Brait SA - and 0.499 - if the portfolio is made entirely of AngloGold Ashanti - according to proportions of the shares held. One expects this portfolio to earn returns that are correlated with the market, but not as extreme. The portfolio value will increase (less so than the market) if the market performs well, but is also partially shielded from declines in the performance of the market.

However, the investor has unknowingly created a portfolio with a worstcase scenario Beta ranging between 1.656 and 0.950, the largest unadjusted Betas for AngloGold and Brait, respectively. The systematic risk of the investor's portfolio has been misestimated. The investor is holding a portfolio where the returns are more pronounced than the market. Market changes will exaggerate the fluctuations in value of the portfolio. Furthermore, the investor could be slow to react to a sharp decline in the market because he/she believes his/her portfolio is weakly correlated with the market. 
The tests of statistical significance reveal that we cannot reject $H_{1}$ for any of the companies. However, different results are reached when testing $\mathrm{H}_{2}$. We can reject $H_{2}$ at the $10 \%$ significance level for 16 out of the 40 of the companies. Furthermore, we can reject $\mathrm{H}_{2}$ at the $5 \%$ significance level for six out of the 40 companies.

The results show that there are companies with significant differences in Beta when the reference-day is changed.

Variation in Beta over reference-days means that investors valuing companies based on future cash flows (dividends) discounted at a risk-adjusted rate, based on the CAPM model, risk inaccurately valuing shares. The investor will overstate the theoretical share price if the Beta is calculated using reference-days that produce a low Beta, resulting in a lower than appropriate discount rate being used, thus valuing the share above the market price. The investor would think this share is priced at a discount, when the market value of the share could reflect its true value.

The fact that 16 of the 40 of the companies considered proved to have at least one pair of Betas that are significantly different at the $10 \%$ level is a concern. There is potential for a large proportion of the total number of shares listed on the JSE to be adversely affected by reference-day risk when estimating systematic risk.

The estimates of systematic risk that most institutional investors use are not the traditional Beta estimates. Therefore, it is important to investigate whether the reference-day variation in systematic risk persists after adjusting the traditional Beta by methods commonly used in practice.

\subsection{Establishing that Reference-Day Risk Persists after Common}

\section{Adjustments}

In this section we establish that Reference-Day Risk persists after Beta is adjusted by the Blume (1971), Dimson (1979) and Vasicek (1973) methods. When testing for the unadjusted Betas, we tested whether the Betas were 
statistically different for each company. The method employed allowed us to test the difference between these regression coefficients, that were a result of different regressions. However, this method cannot be employed for the adjusted Betas as these were not regression coefficients, but rather regression coefficients that had been adjusted. It is for this reason that we use the range of Beta estimates as a measure of reference-day risk.

\subsubsection{Blume (1971)-adjusted Beta}

Beta is calculated for each company, as per Section 4.1, over the periods January 2000 to December 2004 (Period 1) and January 2005 to December 2009 (Period 2), across 20 trading days.

For each trading day we create a linear model with the Period 1 Betas as the explanatory variable and Period 2 Betas as the dependent variable. Blume (1971)-adjusted Betas for the period January 2010 to December 2014 are the values that result from inserting the Period 2 Betas into the model as explanatory variables.

We are unable to calculate the Blume (1971)-adjusted Betas for some of the companies (British American Tobacco, Capitec Bank, Investec PLC, Kumba Iron Ore, Mondi Ltd, Mondi PLC, Reinet Investments, Remgro and Vodacom Group) because of insufficient price history.

The largest range out of the companies investigated is 0.783 (Old Mutual), where the largest Blume (1971)-adjusted Beta is 1.479 and the smallest is 0.696. The smallest range is 0.256 (SAB Miller), where the largest Blume (1971)-adjusted Beta is 0.831 and the smallest is 0.575 .

A summary table showing the Blume-adjusted Betas for all companies can be found in Appendix C.

The Blume (1971)-adjusted Betas increase the reference-day ranges for 19 out of 31 companies, with the range for Old Mutual increasing by $81 \%$. As a result, we conclude that the Blume (1971)-adjustment does not consistently decrease the ranges among Betas conditioned on reference day. 


\subsubsection{Dimson (1979)-adjusted Betas}

We create a multifactor model that models the log returns of a share according to leading, current and lagged log returns of the index. We use one leading and three lagged index return vectors.

The difference between the Dimson (1979)-adjusted Betas and the other adjustments is that the Dimson (1979) method produces negative estimates of systematic risk. For example, the minimum Dimson (1979)-adjusted Beta value seen for Reinet Investments is -0.443 , whereas the minimum unadjusted Beta value for Reinet Investments is 0.346. The Dimson (1979) adjustment is the only method to produce negative estimates of systematic risk. This may be because the Dimson (1979) method corrects for thin trading, so it may be inappropriate in this investigation. This is because the companies being investigated are amongst the most frequently traded on the JSE, thus do not suffer thin trading. If one were interested in Dimson (1979)-adjusted Betas over different reference-days, it would be more suitable to investigate the smaller companies listed on the exchange.

The average range of Dimson (1979)-adjusted Betas is 0.608, which is larger than the unadjusted Betas average range, of 0.449. The ranges of Beta-values increased for 30 out of 40 companies. This suggests that the Dimson (1979) adjustment makes reference-day variation in systematic-risk estimates more pronounced than the unadjusted Beta.

A summary table of Dimson (1979)-adjusted Betas can be found in Appendix D.

\subsubsection{Vasicek (1973)-adjusted Betas}

The prior (sample) mean and variance of the unadjusted Betas is calculated, using the Betas of the investigated companies as the sample.

The variance of company-specific Betas are calculated as described in Section 1. The Vasicek (1973)-adjusted Beta is the weighted averaged of the company's unadjusted Beta and the prior mean, where the weights are according 
to the variance of the company Beta and the sample variance, respectively.

The estimate is described in Section 1.

The Vasicek (1973) method adjusts the unadjusted Beta towards the market average. The resulting Vasicek (1973)-adjusted Betas are similar to those of the unadjusted Betas, as one would expect. The Vasicek (1973) adjustment has reduced the occurrence of extreme differences. The Beta ranges for 35 of the JSE Top 40 companies exhibited lower reference-day ranges than unadjusted Betas. A summary table of Vasicek (1973)-adjusted Betas can be found in Appendix E.

\subsubsection{Comments on Common Adjustments to Beta}

It is difficult to prove statistically significant difference (as we did in Section 4.1) in the adjustments that we investigate. This difficulty is because of the construction of the estimates using the respective adjustments. As a result, we use the relative average range of estimates an indication of the level of reference-day risk.

From what we have observed, it is clear that reference-day risk in estimating the systematic-risk of some companies persist even after common adjustments. A method for estimating systematic risk that is independent of reference-day risk is needed.

4.3 Simulating a Reference-Day Independent Point-Estimate of Systematic Risk

Our primary goal in this paper is to provide a method to estimate a pointestimate (or single value) of Beta that is independent of reference-day. Given twenty estimates of Beta for each company, we may then take the average in order to determine a Beta independent of reference-day. However, this may introduce errors due to small sample size (see Adèr et al (2008:373) for more). In this section, we investigate the feasibility of using a bootstrapped Beta distribution to estimate systematic risk, in which we bootstrap a Beta distribution 
for the companies under investigation. If we were able to recover the underlying Beta distribution, we would use the expected value of the distribution as a point-estimate of the true systematic risk and hence, our primary focus is on the point-estimate of Beta that is independent of reference-day risk. Our focus is not to estimate the distribution of Beta.

We estimate Betas independent of reference-day as follows. Suppose, each share has an underlying Beta value that is not directly observable in the market. Under this assumption of an underlying Beta value, we simulate returns data for both the company and the market-index using the correlation relationship through the Beta-distribution. We simulate 60 sequences of 60 returnspair for the company and the market index. Each sequence of 60 returns-pair are a sequence of returns for 60 months assuming an arbitrary reference day. A Beta estimate may then be calculated for each 60 returns sequence. We, then, chose 20 such sequences such that the variance of Beta for the chosen sequences were maximised. Then, using the simulated returns, we may use a non-parametric bootstrap-approach to estimate an implied Beta estimate, and compare this Beta estimate to the expected value of the originally assumed underlying Beta distribution. Since price is returns in the market, this approach allows us to estimate the underlying Beta.

\subsubsection{Evaluating the Feasibility of Bootstrapping a Beta Distribution}

Index levels and share prices are created under the assumption that index levels and share prices are log normally distributed. Both sequences are based on the same underlying Brownian motion $\left(B_{t} \sim N(0, t)\right)$ so that the level of correlation of log returns between the two sequences (systematic risk) can be controlled.

Suppose the value of the index at time $t$ (in years) is $e^{0.01 t+0.1 B_{t}}$ and the share price at the same time is $e^{0.01 t+0.1 Y B_{t}}$. We assume that the Beta we calculate on a certain reference-day comes from a distribution that arises because of reference-day variation and approximates the true systematic risk. 
Let $Y$ be the distribution assigned to the underlying distribution of Beta. The initial distribution for $Y$ is chosen as $N\left(1.5,0.5^{2}\right)$.

We simulate 60 strings of monthly log returns (of length 60 as in Section 4.1 and Section 4.2) for the company and the index. Each string represents a trading day. We randomly select a share price for each monthly return, out of the possible trading days, and use the random sequence of stock returns and the corresponding index returns to calculate an estimate of systematic risk. The process of randomly selecting elements and calculating Beta is repeated 100000 times per share so that a bootstrapped Beta distribution can be graphed.

The resulting frequency distribution is compared to that of $Y$, following which the effect of changing the parameter values of $Y$ is assessed. We proceed to evaluate the effect of changing the distribution of $Y$ to a uniform distribution and investigate the effects of changing the parameter values of $Y$ on the bootstrapped Beta distribution.

When $Y$ is normal, the simulated mean value is consistently within half a standard deviation of the mean of $Y$. For example, when $Y$ is normal with a mean of 1.5 and standard deviation of 0.5 , the resulting bootstrapped Beta distribution has a mean value of 1.450 . This is shown in Figure 1a, with a $N\left(1.450,0.104^{2}\right)$ distribution fitted in red and the distribution of $Y$ fitted in green.

As the mean parameter of $Y$ is increased, the resulting bootstrapped Beta distributions remain centred within 0.05 of the mean of $Y$. Moreover, the standard deviation of the bootstrapped Beta distributions fluctuate slightly around 0.1 in comparison to the standard deviation of $Y$, which is 0.5 . This is shown graphically in Appendix F.1.

When the standard deviation parameter of $Y$ is increased, the resulting bootstrapped Beta distribution displays an increasing standard deviation as well. Despite the increasing standard deviation, the mean parameter of the bootstrapped Beta distribution remains within half of a standard deviation (standard deviation of the bootstrapped Beta distribution) of the mean of $Y$. 
Appendix F.1 shows the bootstrapped Beta distributions that arise when the standard deviation of the $Y$ is increased steadily.

When $Y$ is changed to a uniform distribution, the resulting bootstrapped Beta distribution remains normal and becomes more concentrated around the mean of $Y$. The standard deviation of the bootstrapped Beta distributions increases steadily as the difference between the parameters of the $Y$ is increased.

Figure 1b displays the resulting bootstrapped Beta distribution when $Y$ is uniform with parameters 1 and 1.5. The bootstrapped Beta distribution is clearly centred closely around 1.25 , the mean value of $Y$. Graphs for different parameter values of the underlying uniform Beta distribution are exhibited in Appendix F.1.
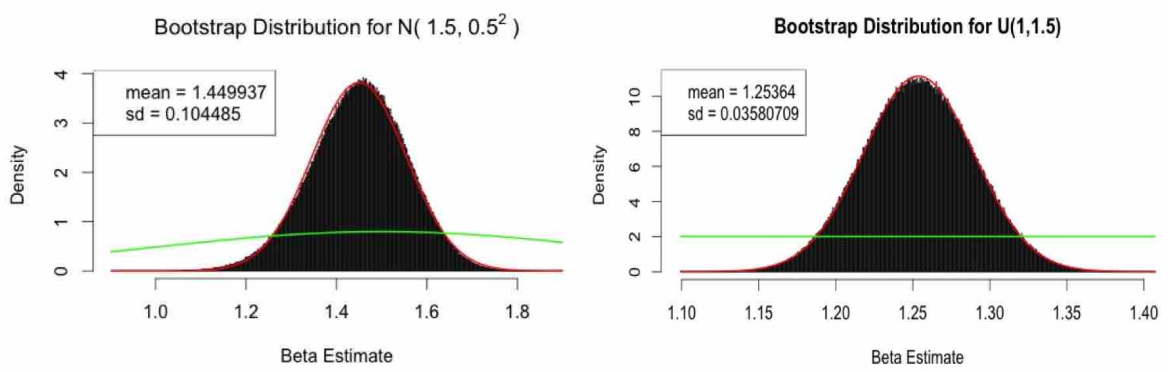

(a) bootstrapped Beta distribution when $Y$ is(b) bootstrapped Beta distribution when $Y$ is normally distributed uniformly distributed

Figure 1: bootstrapped Beta distributions

\subsubsection{Application of the Bootstrapped Beta}

A bootstrapped Beta distribution is generated, as above in Section 4.3.1, for each of the companies under investigation.

The bootstrapped Beta distributions for the companies are normally distributed and centred approximately around the average unadjusted Beta estimates, where the average is calculated over the 20 trading days. 
Figure 2 shows the bootstrapped Beta distributions of AngloGold Ashanti and Mondi Ltd, which had the largest and smallest range in unadjusted Betas, respectively.
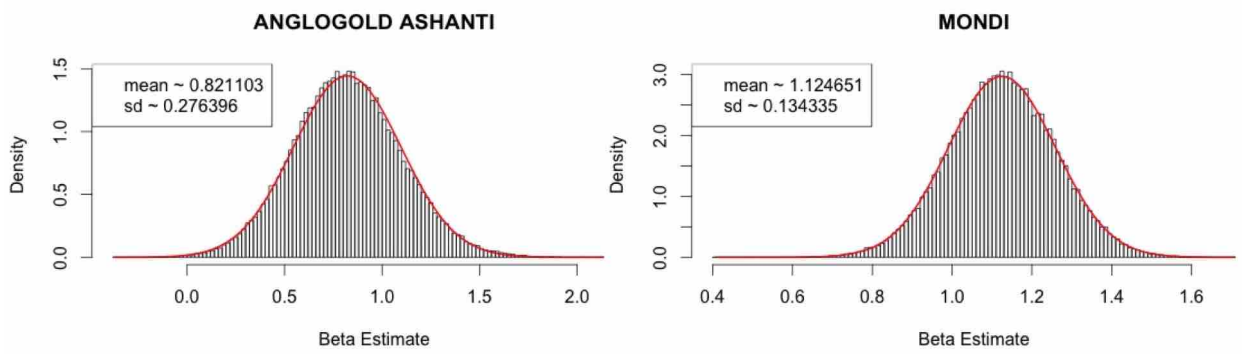

Figure 2: Bootstrapped Beta distribution for the companies with the largest and smallest range in unadjusted Betas

A summary table of the simulated point-estimate of Beta and the results of Vasicek (1973)-adjusted Betas from Section 4.2.3 can be found in Appendix E.

We can infer that the degree of reference-day risk experienced by AngloGold Ashanti is larger than that experienced by Mondi Ltd because of the relative sizes of standard deviation of the distributions in Figure 2. This hypothesis can be confirmed by comparing the relative size of the variance for each company in Appendix B.

The mean values of the bootstrapped Beta distributions are consistent with the sample of unadjusted Betas in Section 4.1, shown in Appendix B. This leads us to propose that the mean value of the bootstrapped Beta distribution provides a reference-day independent estimate of the underlying systematicrisk for a particular share. 


\section{Conclusions}

This paper set out to establish whether there is reference-day risk when estimating systematic risk in the JSE Top 40. We can conclude that reference-day risk exists and creates additional uncertainty for investors who intend to create share portfolios, value companies or manage their capital. This raises the need for an estimate of systematic risk that is reference-day independent.

Having proved the existence of reference-day risk when estimating systematic risk in the JSE Top 40, this paper investigates whether the reference-day variation in estimates persists after being adjusted by the Blume (1971), Dimson (1979) and Vasicek (1973) methods. It is shown that the Blume (1971) and Dimson (1979) adjustments do not reduce reference-day variation in estimating systematic risk. In fact, in some cases the variation is more pronounced, thus further implying the necessity for a reference-day independent estimate of systematic risk.

The final part of this paper set out to simulate a reference-day independent estimate of systematic risk. We first establish that we are able to recover the mean value of a set underlying Beta distribution, but not the standard deviation, by bootstrapping a distribution for Beta using the available monthly returns over all trading days. For the shares on the JSE Top 40, the expected value of a reference-day independent Beta using the bootstrapped method was approximately equal to the average of the twenty Betas estimated for each reference day. Despite this, we assert that the bootstrap method in this paper provides some benefits. Firstly, given the sample size of twenty reference-day dependent Betas, any distortion in the sample may distort the average (i.e., the estimate of the reference-day independent Beta estimated using the average of twenty Betas). Secondly, this work provides a basis for further analysis into estimating the standard deviation of a reference-day independent Beta.

Acknowledgements This work is based on the research supported in part by the National Research Foundation (NRF) of South Africa for the Grant No. 93649. Any opinion, finding and conclusion or recommendation expressed in this material is that of the authors and 
the NRF does not accept any liability in this regard. Additional funding was provided by University of Cape Town Research Office through the Research Development Grant and the Conference Travel Grant.

\section{References}

Acker D, Duck NW (2007) Reference-day risk and the use of monthly returns data. Journal of Accounting, Auditing and Finance 22(4):527 - 557, URL http://search.ebscohost. com/login. aspx?direct=true\&db=buh\& AN $=27157515 \&$ site $=$ ehost - live

Adèr HJ, Adèr M, et al (2008) Advising on research methods: A consultant's companion. Johannes van Kessel Publishing.

Blume ME (1971) On the assessment of risk. Journal of Finance 26(1):1 - 10, URL http://search. ebscohost. com/login. aspx?direct=true\&db=buh\& AN $=4655731 \&$ site $=$ ehost - live

BNP Paribas Cadiz Securities (2014) Estimating betas for JSE-listed companies and indices

Bowie D, Bradfield D (1993) Improved beta estimation on the JSE: a simulation study. South African Journal of Business Management 24:118-123

Bradfield D (2003) Investment basics xlvi. on estimating the beta coefficient. Investment Analysts Journal 57:47-53

Cademartori D, Romo C, Campos R, Galea M (2003) Robust estimation of systematic risk using the $\mathrm{t}$ distribution in the chilean stock markets. Applied Economics Letters 10(7):447, URL http://search.ebscohost.com/ login $\cdot$ aspx?direct=true\&db=buh\&AN=10088858\&site=ehost-live

Cohen KJ, Hawawini GA, Maier SF, Schwartz RA, Whitcomb DK (1983) Friction in the trading process and the estimation of systematic risk. Journal of Financial Economics 12(2):263 - 278, doi: http://dx.doi.org/10.1016/ 0304-405X(83)90038-7, URL http://www.sciencedirect.com/science/ article/pii/0304405X83900387

Dimitrov V, Govindaraj S (2007) Reference-day risk: Observations and extensions. Journal of Accounting, Auditing and Finance 22(4):559 - 572, 
URL http://search. ebscohost. com/login. aspx?direct=true\&db=buh\& $\mathrm{AN}=27157516 \&$ site $=$ ehost - live

Dimson E (1979) Risk measurement when shares are subject to infrequent trading. Journal of Financial Economics 7(2):197 - 226, doi: http://dx.doi. org/10.1016/0304-405X(79)90013-8, URL http://www.sciencedirect. com/science/article/pii/0304405X79900138

Fox J, Friendly M, Weisberg S (2013) Hypothesis tests for multivariate linear models using the car package. R J 5(1):39-52

Gonzalez M, Rodriguez A, Stein R (2014) Adjusted betas under reference-day risk. Engineering Economist 59(1):79 - 88, URL http: //search.ebscohost. com/login. aspx?direct=true\&db=aph\& AN $=94873175 \&$ site $=$ ehost - live

Marsh P (1979) Equity rights issues and the efficiency of the uk stock market. Journal of Finance 34(4):839 - 862, URL http://search.ebscohost.com/ login. aspx?direct $=$ true\&db=buh\&AN=4656321\&site=ehost - live

Scholes M, Williams J (1977) Estimating betas from nonsynchronous data. Journal of Financial Economics 5(3):309 - 327, doi: http://dx.doi.org/ 10.1016/0304-405X(77)90041-1, URL http://www.sciencedirect.com/ science/article/pii/0304405X77900411

Sharpe WF (1963) A simplified model for portfolio analysis. Management Science 9(2):277 - 293, URL http://search.ebscohost.com/login.aspx? direct $=$ true\&db=buh\&AN $=7451896 \&$ site $=$ ehost - live

Vasicek OA (1973) A note on using cross-sectional information in bayesian estimation of security bias. Journal of Finance 28(5):1233 - 1239, URL http://search.ebscohost. com/login. aspx?direct=true\&db=buh\& $\mathrm{AN}=4653778 \&$ site $=$ ehost - live 


\section{Appendices}

\section{A Company List}

The company names are shortened in order to fit the tables. The full company names and corresponding codes are included here.

\begin{tabular}{|ll|ll|}
\hline Company & Code & Company & Code \\
\hline Anglo American Platinum Ltd & AAP & Mondi Ltd & MNL \\
Anglo American PLC & AA & Mondi PLC & MNP \\
AngloGold Ashanti Ltd & AGA & Mr Price Group Ltd & MRP \\
Aspen Pharmaceuticals Holding & ASP & MTN Group Ltd & MTN \\
Barclays Africa Group Ltd & BAR & Naspers Ltd & NAS \\
BHP Billiton PLC & BHP & Nedbank Group Ltd & NED \\
Bidvest Group Ltd & BID & Netcare Ltd & NET \\
Brait S.E & BRA & Old Mutual PLC & OLD \\
British American Tobacco PLC & BRI & Rand Merchant Insurance Holdings & RAN \\
Capital and Counties Prop PLC & CC & Reinet Investments SCA. & REI \\
Capitec Bank & CAP & Remgro Ltd & REM \\
Compagnie Financire Richemont SA & RIC & RMB Holdings Ltd & RMB \\
Discovery Ltd & DIS & SABMiller PLC & SAB \\
FirstRand Ltd & FIR & Sanlam Ltd & SAN \\
Growthpoint Properties Ltd & GRO & Sasol & SAS \\
Intu Properties PLC & INT & Shoprite Holdings Ltd & SHO \\
Investec Ltd & INL & Standard Bank Group Ltd & STA \\
Investec PLC & INP & Steinhoff International Holdings Ltd & STE \\
Kumba Iron Ore & KUM & Tiger Brands Ltd & TIG \\
Mediclinic International Ltd & MED & Vodacom Group Ltd & VOD \\
MMI Holdings Ltd & MMI & Woolworths Holdings Ltd & WOO \\
\hline
\end{tabular}




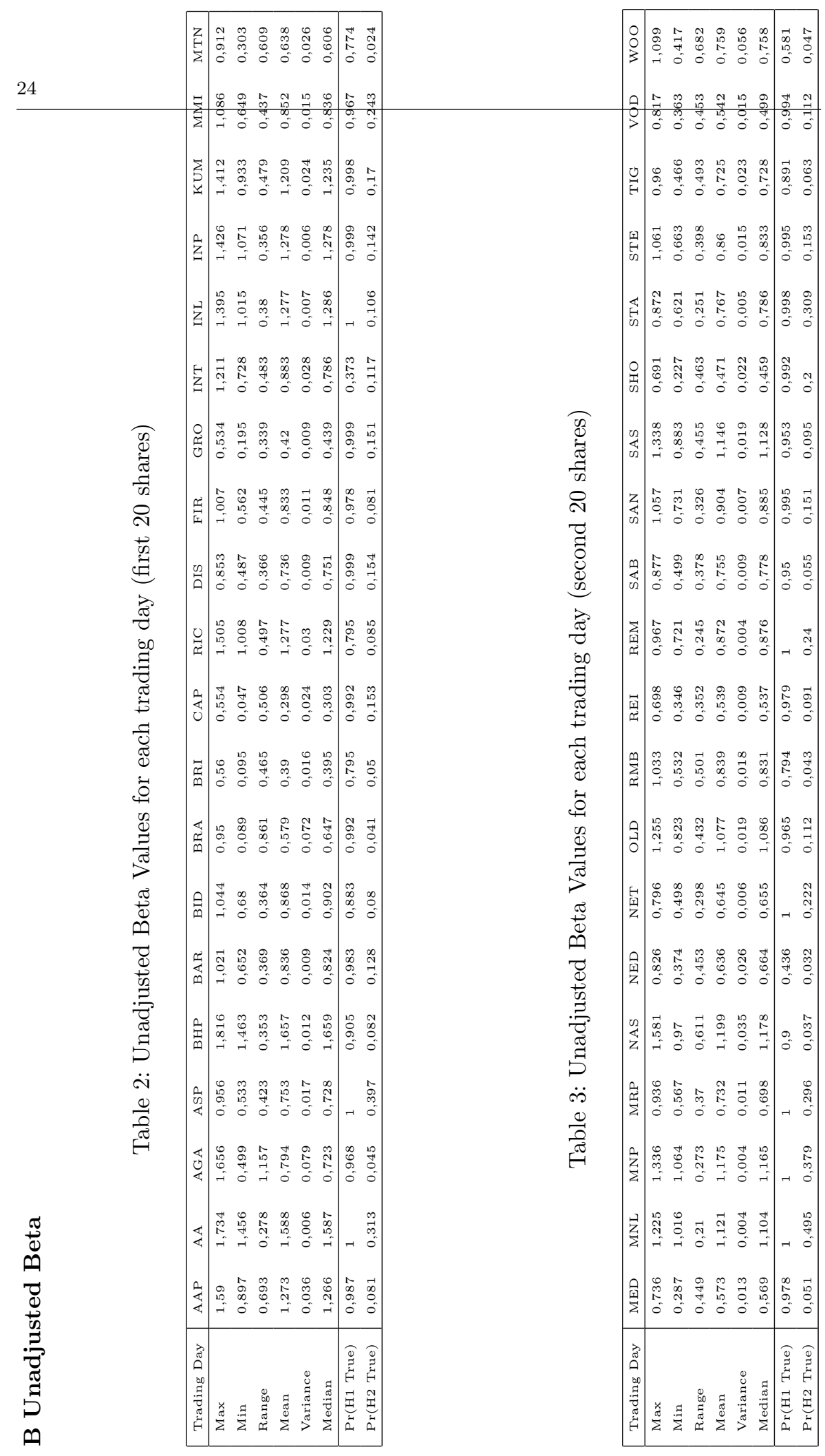




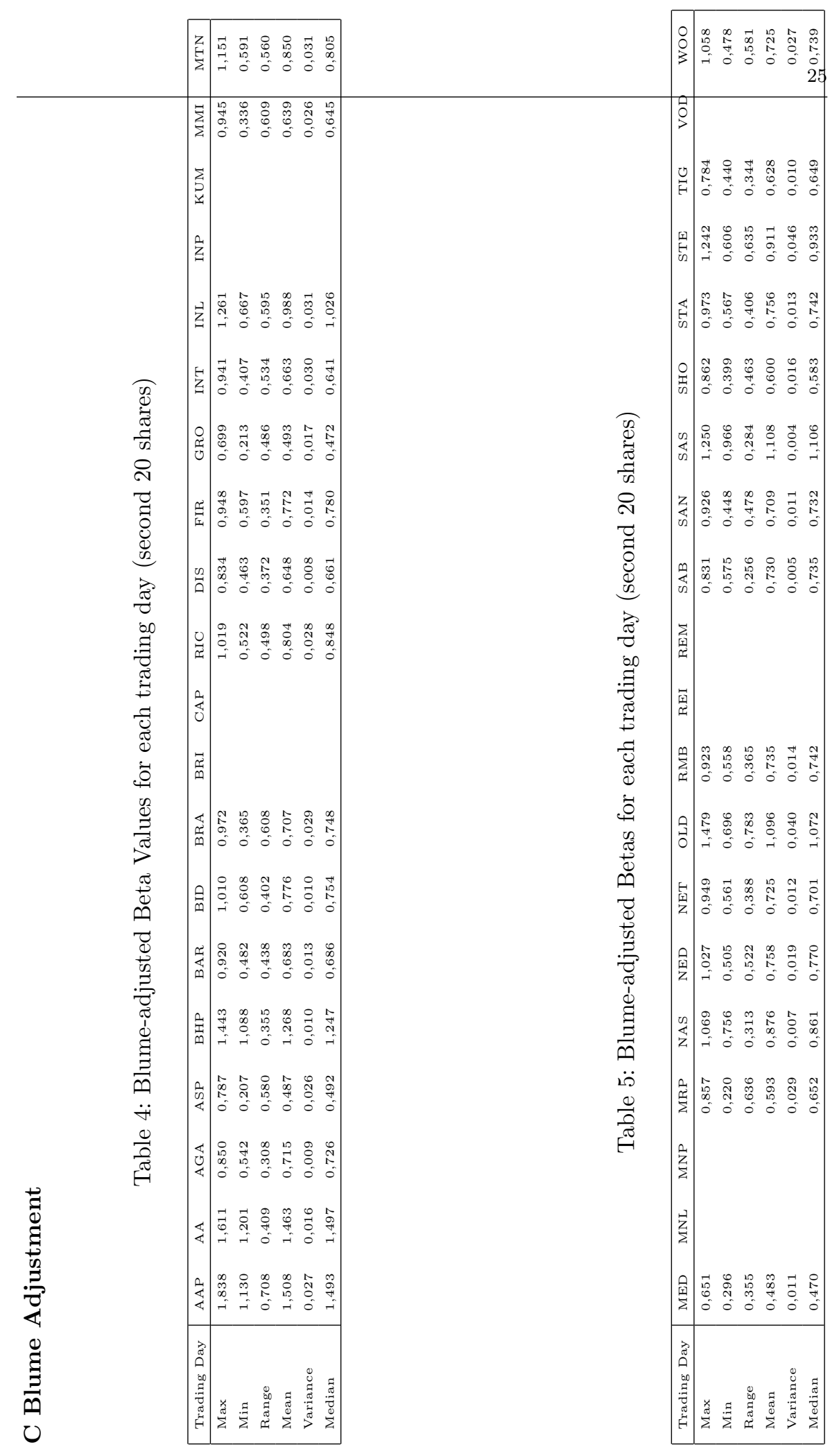




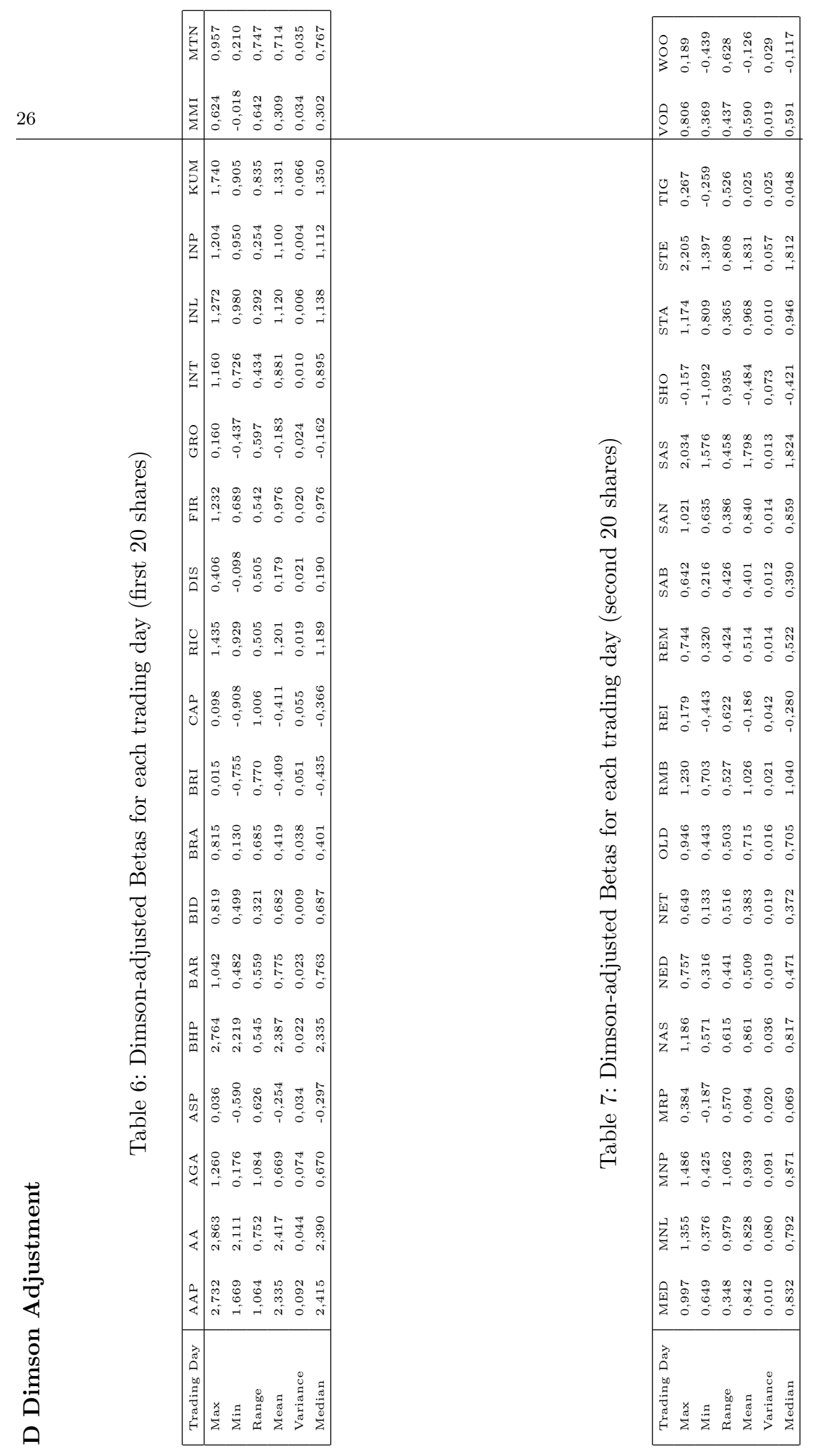




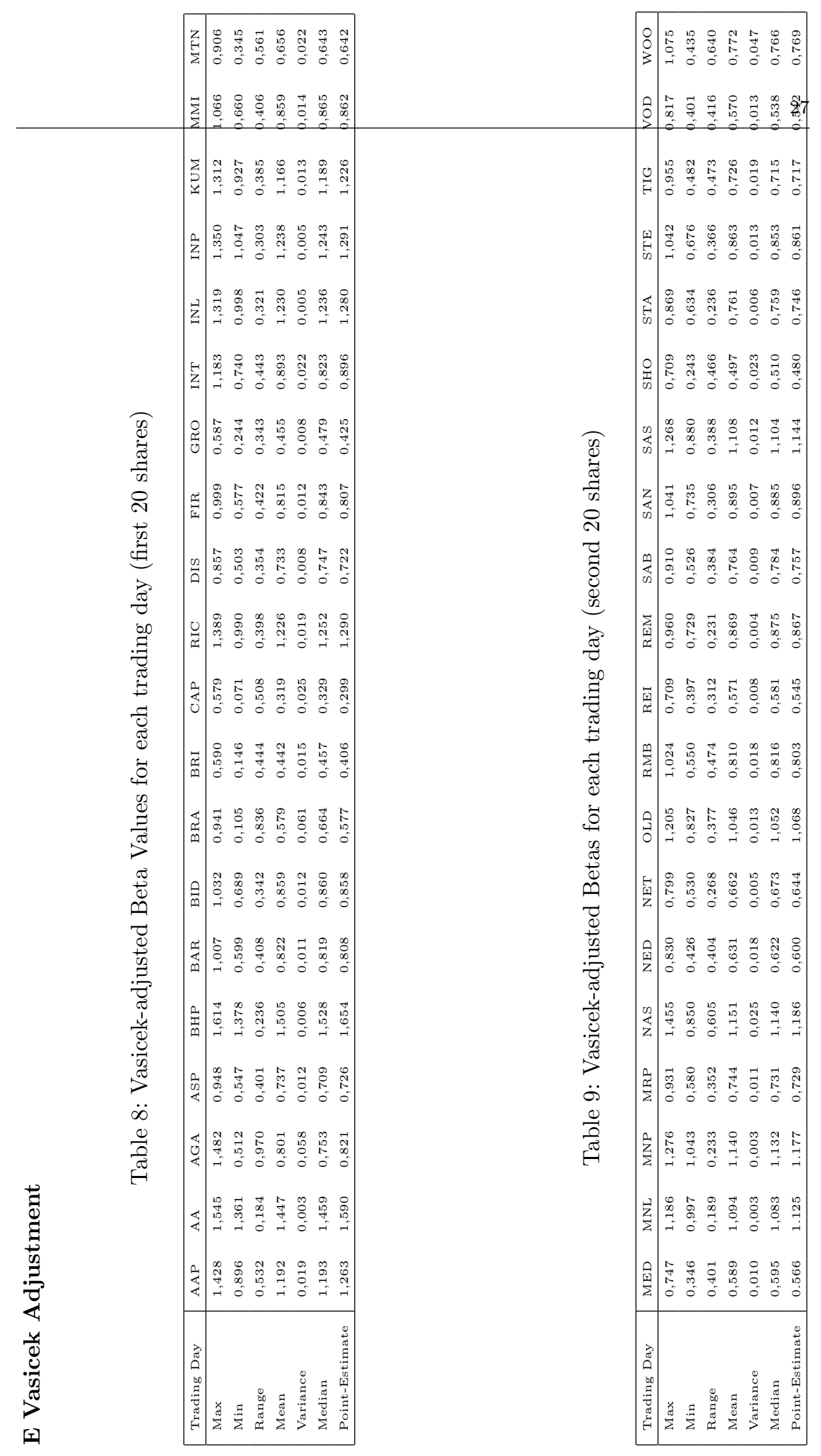




\section{F Bootstrap}

The results from Section 3 are included here.

F.1 Testing Bootstrap Distribution and Parameters

The Bootstrapped Beta distributions that arise from testing changes in the underlying distribution and parameters are included here.

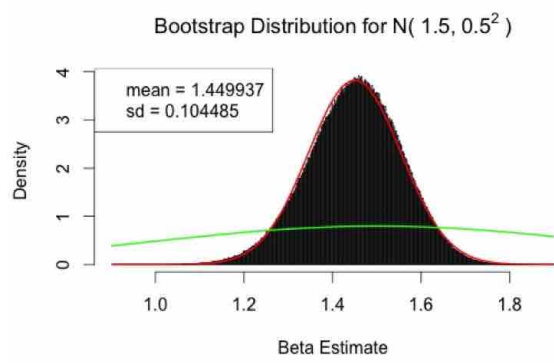

Bootstrap Distribution for $\mathrm{N}\left(1.7,0.5^{2}\right)$

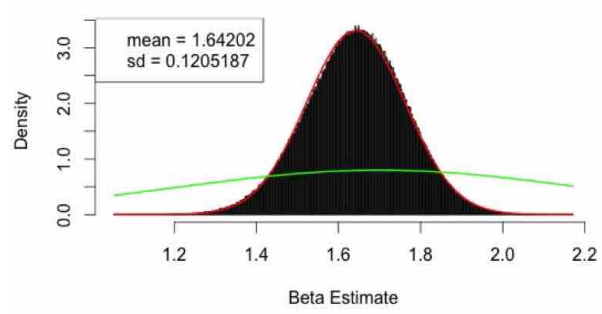

Bootstrap Distribution for N(1.9, $\left.0.5^{2}\right)$

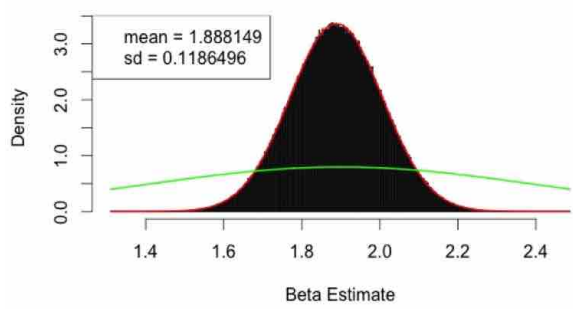

Bootstrap Distribution for $\mathrm{N}\left(1.6,0.5^{2}\right)$

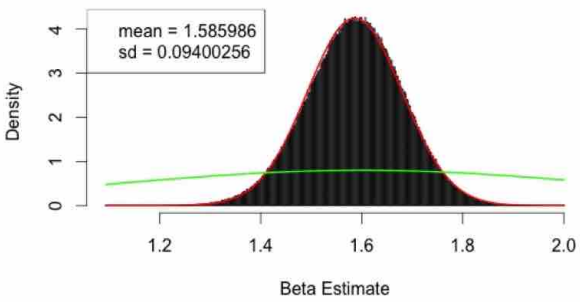

Bootstrap Distribution for $\mathrm{N}\left(1.8,0.5^{2}\right)$

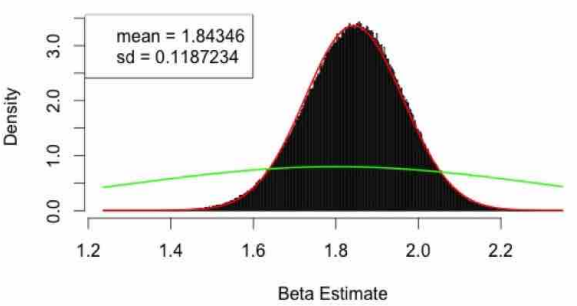

Bootstrap Distribution for $\mathrm{N}\left(2,0.5^{2}\right)$

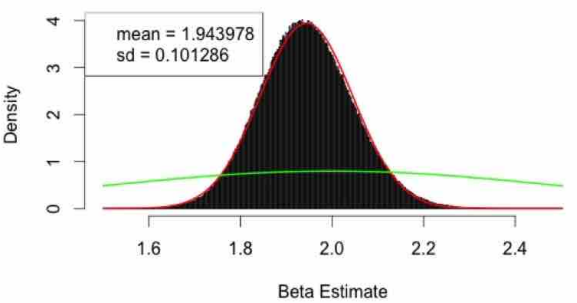




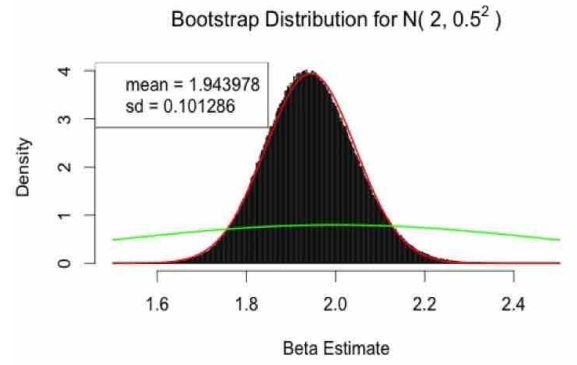

Bootstrap Distribution for $\mathrm{N}\left(2,0.7^{2}\right)$

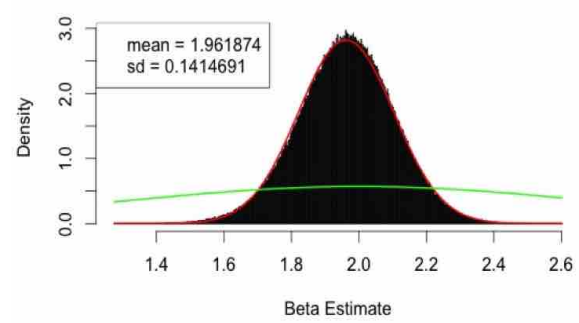

Bootstrap Distribution for $\mathrm{N}\left(2,0.9^{2}\right)$

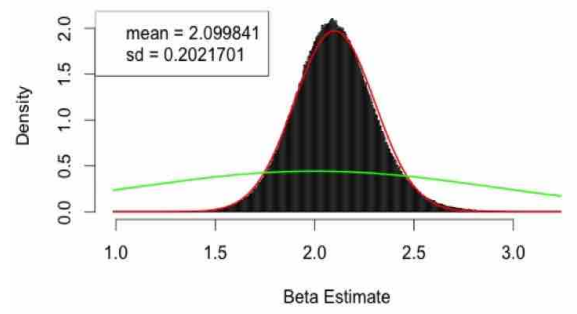

Bootstrap Distribution for $\mathrm{N}\left(2,0.6^{2}\right)$

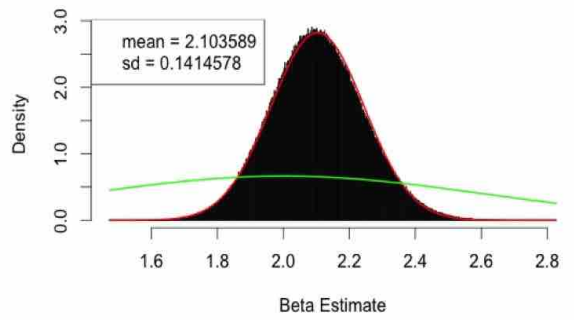

Bootstrap Distribution for $\mathrm{N}\left(2,0.8^{2}\right)$

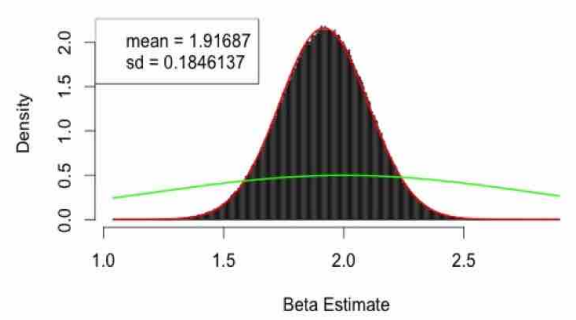

Bootstrap Distribution for $\mathrm{N}(2,1)$

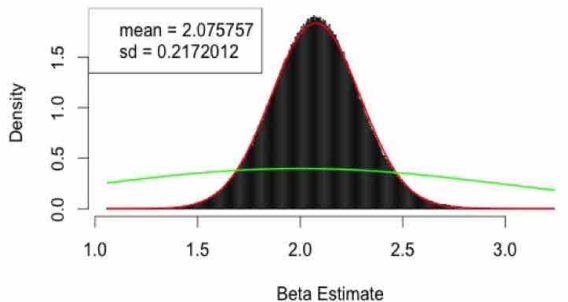


Bootstrap Distribution for U(1,1.5)

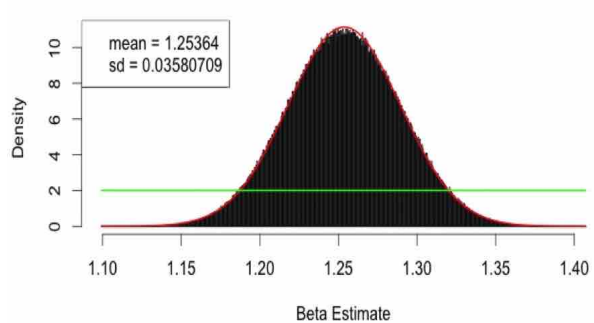

Bootstrap Distribution for $\mathrm{U}(1,1.7)$

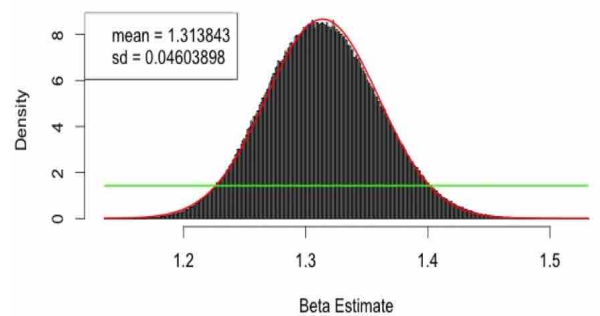

Bootstrap Distribution for U(1,1.9)

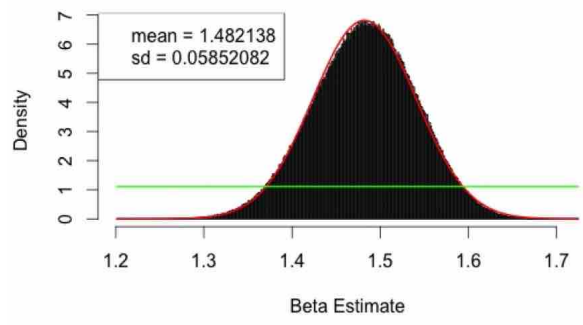

Bootstrap Distribution for U( $1,1.6)$

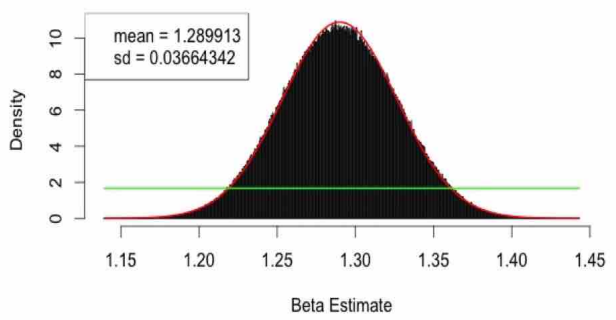

Bootstrap Distribution for $U(1,1.8)$

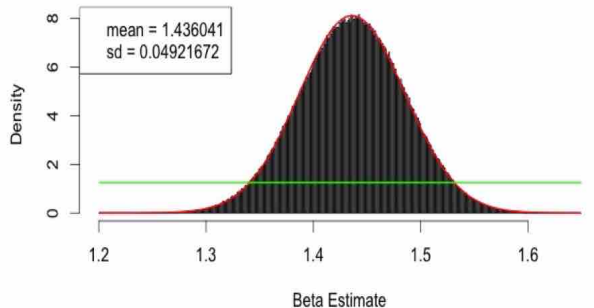

Bootstrap Distribution for $\mathrm{U}(\mathbf{1 , 2})$

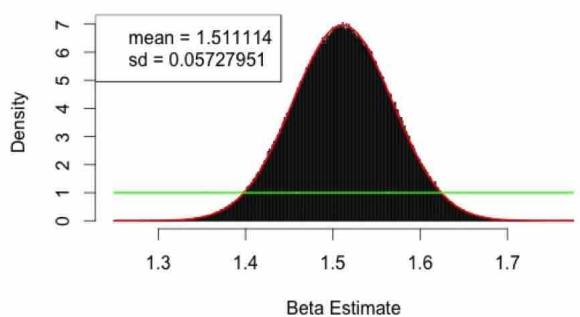

